\title{
Is Deliberation an Antidote to Extreme Partisan Polarization? Reflections on "America in One Room"
}

\author{
JAMES FISHKIN Stanford University, United States \\ ALICE SIU Stanford University, United States \\ LARRY DIAMOND Stanford University, United States \\ NORMAN BRADBURN University of Chicago, United States
}

\begin{abstract}
7 his paper is positioned at the intersection of two literatures: partisan polarization and deliberative democracy. It analyzes results from a national field experiment in which more than 500 registered voters were brought together from around the country to deliberate in depth over a long weekend on five major issues facing the country. A pre-post control group was also asked the same questions. The deliberators showed large, depolarizing changes in their policy attitudes and large decreases in affective polarization. The paper develops the rationale for hypotheses explaining these decreases and contrasts them with a literature that would have expected the opposite. The paper briefly concludes with a discussion of how elements of this "antidote" can be scaled.
\end{abstract}

$\mathbf{T}$ his paper stands at the intersection of two literatures-on partisan polarization and on democratic deliberation-that have not had much connection with one another. If readers find some of the results surprising, the authors have had the same reaction. In this paper we describe these results and our approach to explaining them.

\section{PARTISAN POLARIZATION}

The United States is deeply divided along partisan lines. If representatives stray from the party line on any salient issues, they are pressured at the elite level by party "whips" and threatened at the mass level by activists with being "primaried" (Boatright 2014). At the mass level, scholars debate whether polarization on issues has been increasing (Abramowitz 2013; 2018; Campbell 2016; Fiorina 2009; 2017; Hopkins and Sides 2015), but on some salient issues, divisions along party

James Fishkin (D), Janet M. Peck Chair in International Communication and Professor of Communication and Political Science (by courtesy) and Director, Center for Deliberative Democracy, Stanford University and Department of Communication, Stanford University, United States, jfishkin@stanford.edu.

Alice Siu (I), Associate Director, Center for Deliberative Democracy, Stanford University, United States, asiu@stanford.edu.

Larry Diamond (D), Senior Fellow at the Freeman Spogli Institute for International Studies, Senior Fellow at the Hoover Institution, Professor, by courtesy, of Political Science and Sociology, Stanford University, United States, ldiamond@stanford.edu.

Norman Bradburn (D), Senior Fellow at NORC at the University of Chicago, and the Tiffany and Margaret Blake Distinguished Service Professor Emeritus in the faculties of the University of Chicago's Irving B. Harris Graduate School of Public Policy Studies, Department of Psychology, Booth School of Business and the College at the University of Chicago, United States, Bradburn-Norman@norc.org.

Received: August 18, 2020; revised: January 13, 2021; accepted: June 14, 2021. First published online: July 27, 2021. lines seem increasingly intractable. Further, there is clear evidence that affective polarization has increased at the mass level and this gap in affect reinforces the divisions on substance (Iyengar et al. 2019; Iyengar and Krupenkin 2018; Iyengar, Sood, and Lelkes 2012).

On at least some issues that deeply divide Americans, the lock-step choreography of party elites and mobilizable voters (undoubtedly with causal arrows in both directions - see Jacobs and Shapiro 2000 and Lenz 2012) leads to policy deadlock. The continuing stasis endangers both process and outcome legitimacy (Hetherington and Rudolph 2015).

The divisions are both substantive and affective. Social sorting has accompanied the political sorting of the two major parties, probably increasing the affective gap between them (Mason 2014). Our division into competing political tribes has led to a tribalism of social separation. This, in turn, reinforces political polarization at the mass level and stalemate among policy elites. Affective polarization intensifies political distrust, further fueling the deadlock (Hetherington and Rudolph 2015). Thus, we investigate both the substantive differences on specific policies and affective polarization as measured by feeling thermometer ratings (see Iyengar et al. 2019 for an overview).

\section{EMPIRICAL STUDY OF PUBLIC DELIBERATION}

Over the last three decades, a large literature on "deliberative democracy" has developed both in normative theory and empirical social science (for an overview see Bächtiger et al. 2018). As Goodin argues, "deliberation consists in the weighing of reasons for and against a course of action" (Goodin 2003, 54). But this weighing presumes certain social conditions: "deliberation requires 'weighing' competing arguments for policies or candidates in a context of mutually civil 
and diverse discussion in which people can decide on the merits of arguments with good information" (Fishkin and Mansbridge 2017, 8; see also Bächtiger et al. 2018, 2 for a similar definition).

Broadly sketched, deliberative democracy work has moved from representatives to citizens and from normative theory to the empirical study of deliberation (or the lack of it) by the mass public. While most empirical applications were initially in western democracies, interest in deliberative democracy has engaged many countries, including developing countries (Chirawurah et al. 2019 and some authoritarian ones (He and Warren 2011).

According to some theories of democracy, elected representatives ideally deliberate on the merits regardless of party (Bessette 1994; Burke [1774] 1854). But party discipline gives representatives little opportunity to do so. The prime incentive for elected representatives is to win reelection. They tend to be more interested in winning the election than in winning the argument on the merits.

How about the mass public? Most citizens, most of the time, are not well informed about complex political issues. Such generalizations appear to hold, not only for the US but also for most modern, large-scale democracies (Delli Carpini and Keeter 1996, 89-92). Citizens in mass society seem to have incentives for "rational ignorance" (Downs 1957). If an individual has one opinion in millions, it is unlikely to make a difference, so why pay attention to the complexities of most public issues? Perhaps as a by-product of other activities, an individual can pick up impressions of relevant information and draw inferences (Lupia 1994; Popkin 1991), but most people lack the time to consider issues in depth. The same argument applies to deliberation: If we do not have an effective incentive to acquire information about an issue, we will not want to spend time weighing the arguments for and against it. Rational ignorance and rational nondeliberation are both, at root, part of the same collective action problem for citizens in the large-scale nation-state.

However, such generalizations do not apply to every issue. On occasion, grand debates focus the attention of the public on some salient issue on which the public deliberates to some considerable degree. Perhaps these are the "constitutional moments" Bruce Ackerman identified in the history of the American Republic: the Founding, Reconstruction, the New Deal, or the Civil Rights movement (Ackerman 1993). While these national discussions mostly preceded the development of modern public opinion research, in the case of civil rights there has been a dramatic shift in public opinion over several decades (Page and Shapiro 1992). On some issues the change can be more rapid (for samesex marriage see Rosenfeld 2017).

Generally, "everyday talk," as Jane Mansbridge calls public discussion outside organized settings, can have deliberative qualities but is likely to be less deliberative-less focused on the weighing of competing arguments - than what could be achieved in organized settings (Mansbridge 1999). Empirical studies of public discussion, as distinct from just public opinion, confirm this picture (Conover, Searing, and Crewe 2002).

In everyday talk, citizens are more likely to engage those from similar social locations and who share their political views (Huckfeldt, Mendez, and Osborne 2004; Mutz 2002). They are also likely to consult congenial news sources and get information on social media from their political soulmates. Many will stay within their own "filter bubbles" with social media firms employing algorithms to keep their attention by giving them mostly what they seem to want (Pariser 2011; Sunstein 2017). The explosion of choice has undermined one of the empirical premises of liberal-democratic theory: that liberty will lead to diversity in the airing of different points of view, which will help people think for themselves (or as J. S. Mill put it, achieve "individuality" (Mill [1859] 1962). When people have too much choice, they may well choose the most congenial options and end up exposed to like-mindedness rather than the views they disagree with (Sunstein 2009). After exercising choice, partisans may have little idea what people on the other side are thinking, just as viewers of MSNBC may have little idea what viewers of Fox News are really thinking (and vice versa).

Given the state of everyday talk, the revival of interest in deliberative democracy for the mass public has been driven by a new (and very old) idea: engage a random sample of the relevant population in a design for deliberation where people are effectively motivated to weigh competing arguments on the merits and get good information so as to come to considered judgments. Some theorists advocate this practice on epistemic grounds (Landemore 2013). We offer this approach for its contribution to public will-formation -clarifying the "will of the people" in a world of misinformation and propaganda.

These deliberating microcosms or "minipublics" have various designs. Some versions go all the way back to ancient Athens (Fishkin 2018; Hansen 1991; Manin 1997; Ober 2008). Modern designs vary in the data collected before and after deliberation, in the design of the deliberative process itself, and in the methods of identifying and recruiting random samples (for the challenges of recruitment see Dennis et al. 2020; Neblo et al. 2010). Citizens Juries engage small samples, up to two dozen or so, who deliberate together and try to reach a consensus on recommendations (see Már and Gastil 2019 for their application to ballot propositions in the "Citizens Initiative Review"). Consensus conferences screen volunteers to get 14 or so who self-select from large initial samples (Andersen and Jaeger 1999, 335). Citizens Assemblies gather somewhat larger groups (in British Columbia about 160) and meet for successive weekends, arriving at a recommendation (for British Columbia see Fournier et al. 2011; Warren and Pearse 2008; for more recent citizens assemblies in Ireland see Farrell, Suiter, and Harris 2018; Farrell et al. 2019).

Deliberative Polling employs stratified random sampling, often with control groups and numbers of participants large enough so that both representativeness and opinion changes can be evaluated in a statistically 
meaningful way. Despite these differences, the basic idea that all these approaches share is a response to the limitations of deliberation by the mass public in natural settings. If instead of one opinion in millions, each participant has one opinion in a few hundred, or in a dozen (if the design involves many small groups meeting concurrently), then each participant has a more significant role in the proceedings. Participating in a minipublic rather than just as a member of the public at large recalibrates the scale of interaction so that each individual can plausibly feel more consequential. The process also provides easy access to vetted briefing materials with good information expressing competing sides of the argument. If the several hundred participants are randomly assigned to small groups, these are likely to offer the diversity of viewpoints that most people do not get in ordinary discussion or on social media. Two key features of any minipublic-recalibration of the scale of discussions so that each individual can have a meaningful role and effective engagement of the participants with balanced argumentationaddress two of the key debilitations of everyday talk.

\section{THE "AMERICA IN ONE ROOM" DELIBERATIVE POLL}

This paper focuses on a deliberating microcosm of a certain design-Deliberative Polling. The basic idea is simple. Engage a stratified random sample of the relevant public in good conditions for deliberation about a topic. What would the public really think about an issue if it had the time and opportunity to consider it in depth with balanced and authoritative information, to discuss the pros and cons with diverse others in moderated small groups, to identify questions for panels of competing experts in plenary sessions, and then to come to a considered judgment as expressed in confidential questionnaires? Deliberative Polling has kinship with other methods for bridging civic divides. But unlike Citizens Assemblies, Citizens Juries, or Consensus Conferences, it makes no effort to arrive at a shared consensus or group decision on an issue. Thus, opinions can be studied at the individual level, free of social pressure to go along with the crowd. If a consensus emerges, it will be apparent from the data (the confidential questionnaires) - and it will be an expression of the group's considered judgments.

Why bring the people together for discussion, rather than just provide information? First, when Deliberative Polls have disaggregated the treatment, there was little or no opinion change or evidence of deliberation for those who just received information (Farrar et al. 2010; Sandefur et al. 2020). Second, in a highly partisan context, mere provision of information is likely to "backfire," leading partisans to entrench their views rather than reconsider them (Chong and Druckman 2007; Nyhan and Reifler 2010). Third, our objective is to see what respondents would think about the issues under good conditions for considering them. Provision of balanced information is just one of those good conditions. In addition, deliberation requires that people use that good information to "weigh" competing arguments through civil and diverse discussion, enabling them to decide on the merits of arguments (Fishkin and Mansbridge 2017, 8). Both discussion and information are components of the treatment intended to stimulate the "weighing" of competing arguments (for the actual knowledge gains in this experiment see Table A6 in the online Appendix.)

In advance of the initial survey, an advisory committee reflecting different views on the selected topics vets the briefing materials for balance and accuracy. These materials serve as the initial basis for discussion when the sample is convened to deliberate. The participants discuss each issue with their peers in the small groups, considering the balanced arguments for and against each option.

The first stage of the process resembles a normal public opinion poll: participants are surveyed with a standardized instrument in advance of seeing or discussing any information from the project. In the second stage, the random sample is brought together to a single place for extensive face-to-face discussions, usually over a long weekend. They are randomly assigned to moderated small groups, and they attend plenary sessions where they can pose questions agreed in their small groups to panels of experts or decision makers with diverse views on a particular issue. At the end of the deliberations, participants take the same questionnaire as on first contact, plus added questions for evaluation. Whenever possible, a pre-post control group completes the same questionnaire but does not receive the briefing materials or participate in the discussions. In its full realization, the project is a national field experiment in deliberation.

America in One Room was a national experiment in public deliberation about the major issues facing the country in the period just preceding the 2020 presidential primary season. The event gathered a stratified random sample of 526 registered voters from around the country, recruited by NORC at the University of Chicago. (All but three completed the entire deliberation and the exit survey). A pre-post control group of 844 was also recruited by NORC and took essentially the same questionnaire but did not receive the briefing documents or engage in organized discussions. The registered voter samples for both the treatment and control groups were sourced from NORC's probabilitybased and nationally representative AmeriSpeaks panel. The recruitment and representativeness of the treatment and control groups is discussed in Dennis et al. 2020, in the NORC Methodological Report ${ }^{1}$ and in section 1 of the online appendix.

The deliberations revolved around five broad issue areas, largely selected from a previous NORC survey about the top issues the public hoped to see discussed in the presidential campaign: ${ }^{2}$ immigration, the economy

\footnotetext{
${ }^{1}$ The NORC methodological report is available at https://cdd stanford.edu/mm/2019/10/NORC-Report-for-A1R-2019-Final.pdf.

2 https://apnorc.org/wp-content/uploads/2020/02/2019-The-PublicsPriorities-and-Expectations.pdf.
} 
(including taxes), health care, the environment (including climate change), and foreign policy. Each policy domain discussed at the event included specific policy proposals (47 in all) under active discussion by presidential candidates (some Democrat, some Republican) or other policy makers. The printed briefing materials attempted to concisely present the strongest evidencebased arguments for and against each proposal, and they were also distilled into brief introductory issue videos shown to the participants. The materials were vetted by subject matter experts with opposing perspectives and the nonpartisan Advisory Committee.

The sample gathered in Dallas during September 1922, 2019, arriving Thursday late afternoon and leaving Sunday after lunch. The agenda alternated small group discussions by issue area and plenary sessions, each lasting 90 minutes and running throughout the weekend. Each of the five issue domains was discussed both in small group discussions and in plenary sessions with experts responding to questions agreed in the small groups. Participants remained with the same small group (averaging about 13 persons) throughout the event, enabling them to get to know one another on a personal level over the course of the weekend. In the final questionnaire, completed just before departure, respondents were asked (as they had been in the predeliberation survey) to rate each specific policy proposal on a 0 to 10 scale, where 0 was "strongly oppose," 10 was "strongly favor," and 5 was the midpoint. ${ }^{3}$ The control group took the same questionnaire within the same approximate period.

Of the 47 proposals, we classify 26 as instances of extreme partisan polarization between Republicans and Democrats. Our criteria are as follows:

(a) At least $15 \%$ of each party takes the strongest possible position ( 0 or 10$)$ at time 1 , with these Democrats and Republicans at opposite poles on the proposal.

(b) A majority of those party members who take a position at time 1 are on the same side of the scale as those taking the strongest positions in favor or against.

These two criteria combine to identify extreme partisan polarization because those taking the strongest positions are balanced at the two poles, Republicans on one side, Democrats at the other. The majority support on either side is also symmetrical. A majority of Republicans are on one side and a majority of Democrats are on the other. ${ }^{4}$

Do issues of extreme partisan polarization depolarize when subjected to certain kinds of public deliberation? What do we mean by depolarization? How do

\footnotetext{
3 "Strongly" referring to extremity on the scale and not "attitude strength" (Petty and Krosnick 1995).

${ }^{4}$ Party membership is based on the standard battery of party selfidentification for the two major parties. Independents were asked whether they lean Republican or Democrat. Results for party members plus leaners are presented in the online appendix (Table A4).
}

movements by members of a given party relate to movements by members of the other party (assuming something like the US context with two major parties). These two questions suggest two kinds of depolarization:

(a) One-sided depolarization: when the majority of members of a given party are on one side of the partisan divide and a majority of members of the other party are on the other side, one-sided depolarization occurs if the mean position of the members of one party moves toward the midpoint or crosses it, whereas the mean position of the members of the other party shows no significant movement toward the midpoint.

(b) Two-sided depolarization: when the majority of members of a given party are on one side of the partisan divide and a majority of members of the other party are on the other side, two-sided depolarization occurs if the means of both parties move closer together on the scale or if they move to the same side of the scale.

In other words, if the partisans of only one party moderate toward the midpoint then it is one-sided depolarization. But if the partisans of both parties move toward each other it is two-sided depolarization.

Suppose that after deliberating, members of one party, say Republicans, move their mean position from opposition to support for a proposal while Democrats intensify their degree of support. In that case, partisans of the two parties might not end up closer together in their mean position (because Democrats moved further in their support than Republicans did in developing support). Nevertheless, in this hypothetical situation, we consider the two parties ending up on the same side of the issue to be sufficient to constitute depolarization. The mean positions of the two sides no longer disagree about whether a proposal should be supported or opposed. They only disagree on how strongly to support or oppose it. Thus we can speak of two forms of depolarization: changing distance (so that the two parties end up closer in their mean positions on the 0 to 10 scale) and changing sides (so that the two parties end up on the same side of an issue).

\section{RESEARCH QUESTIONS}

The literature offers a basis for contrasting expectations about what is likely to happen when discussion takes place across party lines on issues where the two parties are highly polarized. What will be the effect on issue-based polarization among party members and, in particular, among party members taking the strongest possible positions at opposite ends of the scale? In addition, what is the influence on affective polarization? The increasing dislike that supporters of the two parties feel for each other has evidently intensified our state of deadlock and division (Hetherington and Rudolph 2015). The growing literature on affective 
polarization shows that it is distinct from issue-based polarization (Iyengar et al. 2019). We can distill these topics into a series of research questions and hypotheses.

\section{Research Question 1: On issues of extreme partisan polarization, will cross-party discussion lead to more or less polarization on those issues?}

When members of opposing parties discuss issues that are highly polarized along partisan lines, will partisan-based polarization on the issues increase or decrease? In other words, will the mean positions of each party move farther away from each other or closer together?

Consider two arguments predicting increased polarization from cross-party discussion on issues that are already highly polarized. The first expects that partisanship will fuel "directional" or "partisan"-motivated reasoning. As Taber and Lodge found, partisans "counterargue the contrary arguments and uncritically accept supporting arguments, evidence of a disconfirmation bias." Also, by seeking out supporting arguments they will tend to exhibit confirmation bias (Taber and Lodge 2006, 755). These patterns are both part of directional motivated reasoning to support positions they are already invested in (Kunda 1990). Such processes are thus likely to push party members to more extreme positions on each side of the polarized divide (Druckman 2012; Leeper and Slothuus 2014; Levendusky, Druckman, and McClain 2016). Even mere exposure to information one disagrees with often "backfires" in a partisan context, increasing disagreement (Chong and Druckman 2007; Nyhan and Reifler 2010).

Sunstein's "law of group polarization" provides a second argument that discussion is likely to increase polarization, especially on issues that already exhibit deep divisions. Building on earlier work with small groups, he and his collaborators identify two causal factors supporting increased polarization - the "imbalance in the argument pool" and a "social comparison effect" (Sunstein 2002; 2009). More recently he has generalized the problem from juries and jury-like settings to the condition of the citizen in mass society (Sunstein 2017). Republicans live in one social world, Democrats in another. Because of partisan selectivity, the bias in our social media "news feeds" and the algorithms in our "filter bubbles," partisans are especially likely to get a strong imbalance in the argument pool (Pariser 2011; Sunstein 2009). Weighing those unbalanced arguments, they are likely to move toward a more polarized position in the direction supported by the imbalance. Further, the social comparison effect (as they compare their views to those of their friends, associates, and fellow partisans; Asch 1955) will, in effect, create bandwagon effects (Goidel and Shields 1994), a spiral of silence (Noelle-Neumann 1984), and added pressure to move to the extreme of the side they were already on.

These arguments apply most clearly to unstructured everyday talk and cross-party encounters in natural settings. However, the deliberative minipublic investigated here, the Deliberative Poll, designs very different conditions for cross-partisan engagement on the issues. We expect that it will decrease rather than increase polarization because it supports different expectations about both motivated reasoning and the law of group polarization.

As Kunda first hypothesized, there are two kinds of "motivated reasoning"- "directional" and "accuracy based" (Kunda 1990). The argument that discussion will increase partisan polarization on issues that are already polarized relies on directional-motivated reasoning. But if an experimental treatment could encourage the second kind of motivated reasoningaccuracy-based-then reasoning on the merits would likely result. Further, if on issues of partisan polarization, people have arrived at positions without seriously considering (or even encountering) arguments on the other side, then we might well expect accuracy-based reasoning to reduce partisan polarization by overcoming the legacy of previously one-sided reasoning. The expectation here is not that deliberation will always depolarize but that it will likely depolarize on issues where participants begin the exercise with high levels of partisan polarization.

Kunda concluded that subjects were motivated to be accurate when they "expected to be evaluated, expected to justify their judgments, expected their judgments to be made public or expected their evaluations to affect the evaluated person's life" (Kunda 1990, 481). When people think their views will matter, and when they have to share the reasons supporting their views, they become more attentive to accuracy goals.

These are precisely the motivations that the Deliberative Poll is designed to foster. The task of the small groups is to discuss the arguments for and against each policy proposal and then formulate group questions for the balanced panels of competing experts in the plenary sessions, all so that the participants can come to their own, individually considered judgments. The design also allows groups to submit additional questions to neutral fact checkers who reply during the deliberations. Thus, it encourages the small groups to seek and weigh relevant information and come to their individual considered judgments.

A parallel argument can be made about how the Deliberative Poll blunts the directional force of Sunstein's "law of group polarization" (Sunstein 2009, 5557). The design engages the small group discussions with balanced materials, presenting pros and cons for each proposal. On each proposal, the moderators of the small group discussions attempt to cover the agenda of competing arguments in the briefing materials and to solicit added arguments from the randomly assigned members. Moderators are trained not to give any hint of their own views (Siu and Stanisevski 2012). ${ }^{5}$ The

\footnotetext{
${ }^{5}$ For an evaluation of the moderators, see Table A4 in the online appendix. More than $90 \%$ of all participants (and separately of Republicans, Democrats, and Independents) disagreed strongly that "my moderator sometimes tried to influence the group with his or her own views."
} 
plenary sessions are also balanced, featuring experts representing alternative views. These design features should minimize the problem of imbalances in the argument pool. As for the social comparison effect, the participants only express their final judgments in confidential questionnaires. The moderators encourage the participants to consider, and give voice to, arguments on either side without ever having to express their final decision. There is no "show of hands" or other voting on the proposals. Thus, the social pressures to go along with the crowd should be blunted.

The Deliberative Poll can thus be expected to blunt the dynamics of both directional-motivated reasoning and imbalanced argumentation, dynamics that might otherwise increase polarization (Grönlund, Herne, and Setälä 2015). But blunting the dynamics toward more polarization is not the same as depolarizing. Balanced argumentation might be expected to produce no aggregate net change (see Barabas 2004, 695). Why would the process actually depolarize on issues of high partisan polarization? Our expectation is that partisans have developed their views going into the deliberations on the basis of one-sided argumentation, without ever having taken seriously, or perhaps even having considered, the arguments on the other side of the partisan divide. If the design of the treatment can stimulate accuracy-based motivation and get them engaged thoughtfully with the other side, partisan participants are likely to adjust and move in the direction of the other party.

Therefore, we hypothesize the following:

H1 On issues of extreme partisan polarization, deliberation with an appropriate design will depolarize substantive differences between the parties.

This depolarization can be one-sided, with just one set of party members moving toward the midpoint (or past it). Or, it can be two-sided, with the means of both parties moving closer toward each other (or to the same side of the midpoint on that issue).

This hypothesis is formulated in terms of party members for the two main parties. Consider now not just party members in general but those party members who take the strongest position at either end of the scale. Should we also expect them to depolarize?

We might expect them to be the least likely to depolarize. Their previous thinking has already pushed them as far as possible to the limits of the scale. Their partisan loyalties have likely supported motivated reasoning and imbalanced argumentation in their natural environments. Of all the partisans on either side, it seems we should expect them to be the most dug in (see Wojcieszak 2011, 605, who found the extremes becoming even more so on a battery of questions).

Still, there is another perspective. If the design of the treatment stimulates accuracy-based motivated reasoning and balanced argumentation, those initially taking the strongest positions on the scale could also be susceptible to change. The very fact that in their natural environments they have arrived at such polarized positions may suggest they have been least exposed previously to serious engagement with the other side of the partisan divide. At least on these issues of high partisanship, they may be fully as susceptible to depolarization as those taking more moderate positions. This idea suggests the next hypothesis:

H2 On issues of extreme partisan polarization, deliberation with an appropriate design will depolarize substantive differences among those members of each party who took the most polarized positions before deliberation.

"Most polarized" refers to those taking a position of 0 or 10 on an issue that satisfies our criteria for extreme partisan polarization. Again, this depolarization could encompass just the proponents on one side or it could be two-sided so that the means of the two groups who take maximum positions at either side of an issue move closer together (or move to the same side).

Now let us turn to affective polarization. Will the same pattern hold?

Research Question 2: On issues of extreme partisan polarization, will cross-party discussion lead to more or less affective polarization?

It could be argued that cross-party discussion on issues of partisan polarization will likely exacerbate affective divisions between the parties by triggering the dynamics of in-group/out-group identity that increase hostility toward the out-group (the other party; Tajfel 1981). Stimulating outrage across the partisan divide has become a major part of our political culture in traditional media, social media, and campaign advertising (Berry and Soberieraj 2014; Mutz 2015).

However, the same deliberative design that we believe fosters accuracy-based motivated reasoning and balanced argumentation can also be expected to reduce affect. A line of research about contact across deep divisions indicates that under certain conditions, "contact yields liking," or decreased affective polarization. Not just any contact but contact satisfying certain conditions. Going back to pioneering work by Allport (1954), a design that fosters "equal status between groups, common goals, cooperation and institutional support" (Pettigrew and Tropp 2011, 75-6) for the importance of the interactions will likely lead the two groups to a reduction in prejudice. These four conditions are not all essential, but in meta-analyses they were held to work best in combination (Hewstone and Swart 2011; Pettigrew and Tropp 2006; 2011).

The deliberative design employed in "America in One Room" intentionally fosters equal status, emphasizing that everyone's opinion counts and deserves to be listened to. It encourages the participants to cooperate together to consider competing arguments and come to their own informed conclusions. It engages the participants in a common effort to develop and pose questions of greatest concern for presentation on behalf of their group in the plenary sessions. And, it 
offers institutional support for these efforts, while the evident media interest in the event added to the sense of informal support for the project.

The contact hypothesis has not previously been applied to the Deliberative Poll treatment for the question of change in affect. However, it has been applied to changes in policy attitudes affecting the Roma in Bulgaria and the Aboriginals in Australia. In those projects the dependent variables were policy proposals affecting the minority groups (more favorable treatment of the Roma or the Aboriginals; Kim, Fishkin, and Luskin 2018). In Northern Ireland, the Deliberative Poll influenced community perceptions (Protestants and Catholics each viewed the other community as more "trustworthy" and "open to reason" (Luskin et al. 2014). Other organized discussions provide support for the contact hypothesis in cases of extreme group division such as between Israelis and Palestinians (Maoz 2000).

On this basis we hypothesize the following:

H3: On issues of extreme partisan polarization, deliberation among members of different parties conducted with an appropriate design will reduce affective polarization.

Following deliberation, partisans' thermometer ratings for the opposite party will increase or the gap between thermometer ratings for one's own party and the opposing one will diminish. The group discussions, moderated to ensure mutual respect and a context of equality, combined with the common task of formulating questions for the competing experts will lower the temperature of the heated partisan divisions and change the way the in-group feels about the out-group.

This hypothesis applies generally to people who identify with one party or the other. What of those who take the strongest positions on either side of the partisan divide? Will affective polarization attenuate among them as well? In theory, the psychology of ingroup/out-group division should be even stronger for those who take the strongest positions, so one might expect them to be less susceptible to the contact hypothesis. On the other hand, they might be the very people who have had less contact, or at least less contact under constructive conditions, with members of the other party. Hence, we might expect the contact hypothesis to come into play for them as well:

H4: On issues of extreme partisan polarization, deliberation among members of different parties conducted with the appropriate design will reduce affective polarization among those in both parties initially taking the most polarized positions on the issues.

\section{WHAT HAPPENED?}

Again, 26 of the 47 policy proposals fit our criteria for extreme partisan polarization. The magnitude of the depolarizing changes on such contentious issues deserves attention. The results for all 26 proposals are in Tables 1-5.
Table 1 shows the opinion changes by party for the five polarized proposals on immigration. For each question, the table shows the means before and after deliberation for Democrats and Republicans overall and for the most polarized (those Democrats and Republicans answering either 0 or 10 before deliberation). In almost every case, the changes are statistically significant not only for the treatment group but also in the difference-in-difference analyses that include the control group. The control group showed very little substantive change between T1 and T2. Comparisons to the control group are presented in the online Appendix (Table A3). These changes are for party members. We observe similar changes when the "lean Republicans" are included with the Republicans and the "lean Democrats" are included with the Democrats. Those results are in the online Appendix (Table A4).

\section{IMMIGRATION}

On immigration, all five of the proposals exhibiting extreme partisan polarization produced massive changes with deliberation. For example, on question 2a "Reduce the number of refugees allowed to resettle in the US," $65 \%$ of Republicans initially supported this proposal (mean 7.05 on the 0 to 10 scale). This support dropped 31 points to $34 \%$ (mean 4.72 ) after deliberation. On the Democrat side, opposition to this proposal increased significantly from $58 \%$ (mean of 3.3 ) to $75 \%$ (2.39), an increase of 17 points. The mean position of Republicans who initially took the most polarized position (in favor) went from 10 to 6.49 , whereas the mean position for Democrats who initially took the most polarized position in opposition went from 0 to 0.725. Republicans and Democrats and those taking the most polarized positions moved significantly closer together as shown in the last column of Table 1. This pattern applies to all five immigration proposals.

Another highly contested proposal on immigration was the proposal to continue DACA (the Deferred Action for Childhood Arrivals program). Among Republicans, only 36\% (mean 4.64) supported this proposal before deliberation. After deliberation, Republican support rose 25 points to $61 \%$ (mean 6.11). Support among Democrats also increased from the initially high level of $89 \%$ (mean 8.74 ) to $95 \%$ (mean 9.25). The mean position of Republicans who initially took the strongest position in opposition went from 0 to 3.667, whereas Democrats who initially took the strongest position in favor moved only slightly from it (to 9.787). Overall, Republicans and Democrats not only moved closer together but also moved to the same side of the issue, as Republicans changed from opposition to support for DACA.

A third immigration topic was perhaps the most intensely contested of the polarized proposals: "Undocumented immigrants should be forced to return to their home countries before applying to legally come back to the US to live and work permanently." Before deliberation support for this proposal among 


\section{TABLE 1. Immigration}

\begin{tabular}{|c|c|c|c|c|c|c|c|c|c|c|}
\hline \multirow[b]{2}{*}{ No. } & \multirow[b]{2}{*}{ Question } & \multicolumn{3}{|c|}{ Pre } & \multicolumn{3}{|c|}{ Post } & \multicolumn{3}{|c|}{ Post - Pre } \\
\hline & & Dem & Rep & $R-D$ & Dem & Rep & $R-D$ & Dem & Rep & $R-D$ \\
\hline \multirow[t]{2}{*}{ Q2A } & $\begin{array}{l}\text { [Reduce the number of refuges allowed } \\
\text { to resettle in the US.] }\end{array}$ & 3.300 & 7.050 & $3.750^{\star \star \star}$ & 2.390 & 4.720 & $2.330^{\star \star \star}$ & $-0.910^{\star \star \star}$ & $-2.330^{\star \star \star}$ & $-1.420^{\star \star \star}$ \\
\hline & Most polarized & 0.000 & 10.000 & $10.000^{\star \star *}$ & 0.725 & 6.490 & $5.765^{\star \star \star}$ & $0.725^{\star \star \star}$ & $-3.510^{\star \star \star}$ & $-4.325^{\star \star \star}$ \\
\hline \multirow[t]{2}{*}{ Q2C } & $\begin{array}{l}\text { [Provide aid to reduce poverty and } \\
\text { violence in Central America.] }\end{array}$ & 7.450 & 3.770 & $-3.680^{\star \star \star}$ & 7.190 & 4.730 & $-2.460^{\star \star \star}$ & -0.260 & $0.960^{\star \star \star}$ & $-1.220^{\star * *}$ \\
\hline & Most polarized & 10.000 & 0.000 & $-10.000^{\star \star \star}$ & 8.375 & 2.652 & $-5.723^{\star \star \star}$ & $-1.625^{\star \star *}$ & $2.652^{\star \star \star}$ & $-4.277^{\star \star \star}$ \\
\hline \multirow[t]{2}{*}{ Q2E } & $\begin{array}{l}\text { [Increase the number of visas for low- } \\
\text { skilled workers to move to the US for } \\
\text { industries that need them, like } \\
\text { agriculture and service.] }\end{array}$ & 7.280 & 4.520 & $-2.760^{\star \star \star}$ & 8.170 & 6.380 & $-1.790^{\star \star \star}$ & $0.890^{\star * \star}$ & $1.860^{\star \star \star}$ & $-0.970^{\star \star \star}$ \\
\hline & Most polarized & 10.000 & 0.000 & $-10.000^{\star \star \star}$ & 9.211 & 4.333 & $-4.878^{\star \star \star}$ & $-0.789^{* * *}$ & $4.333^{\star \star \star}$ & $-5.122^{\star * *}$ \\
\hline \multirow[t]{2}{*}{ Q2H } & $\begin{array}{l}\text { Continue DACA, [the Deferred Action for } \\
\text { Childhood Arrivals program, which } \\
\text { protects people who were brought to } \\
\text { the US as children when their parents } \\
\text { entered the country illegally.] }\end{array}$ & 8.740 & 4.640 & $-4.100^{\star \star \star}$ & 9.250 & 6.110 & $-3.140^{\star * \star}$ & $0.510^{\star \star \star}$ & $1.470^{\star \star \star}$ & $-0.960^{* \star *}$ \\
\hline & Most polarized & 10.000 & 0.0 & $-10.000^{\star \star \star}$ & 9.787 & 3.667 & $-6.120^{\star \star \star}$ & $-0.213^{\star}$ & $3.667^{\star \star \star}$ & $-3.880^{* * *}$ \\
\hline \multirow[t]{2}{*}{ Q2I } & $\begin{array}{l}\text { [Undocumented immigrants should be } \\
\text { forced to return to their home countries } \\
\text { before applying to legally come to the } \\
\text { US to live and work permanently.] }\end{array}$ & 3.3 & 7.9 & $4.670^{\star \star \star}$ & 2.44 & 5.32 & $2.880^{\star \star \star}$ & $-0.820^{\star * \star}$ & $-2.610^{\star \star \star}$ & $-1.790^{\star \star \star}$ \\
\hline & Most polarized & 0.000 & 10.0 & $10.000^{\star \star *}$ & 0.870 & 6.621 & $5.751^{\star \star \star}$ & $0.870^{\star *}$ & $-3.379^{\star \star \star}$ & $-4.249^{\star * *}$ \\
\hline
\end{tabular}

Note: ${ }^{*} p<0.05,{ }^{* \star} p<0.01,{ }^{\star \star \star} p<0.000$. 


\section{TABLE 2. Environment}

\begin{tabular}{|c|c|c|c|c|c|c|c|c|c|c|}
\hline \multirow[b]{2}{*}{ No. } & \multirow[b]{2}{*}{ Question } & \multicolumn{3}{|c|}{ Pre } & \multicolumn{3}{|c|}{ Post } & \multicolumn{3}{|c|}{ Post - Pre } \\
\hline & & Dem & Rep & $R-D$ & Dem & Rep & $R-D$ & Dem & Rep & $R-D$ \\
\hline \multirow[t]{2}{*}{ Q3A } & $\begin{array}{l}\text { [The US should commit to the } 2014 \text { Paris } \\
\text { Agreement to combat climate change.] }\end{array}$ & 8.9 & 3.7 & $-5.210^{\star \star \star}$ & 9.06 & 4.54 & $-4.520^{\star * \star}$ & 0.130 & $0.820^{\star *}$ & $-0.690^{\star * *}$ \\
\hline & Most polarized & 10.000 & 0.000 & $-10.000^{\star * *}$ & 9.608 & 2.27 & -7.338 & $-0.392^{\star * *}$ & $2.270^{\star \star *}$ & $-2.662^{* * *}$ \\
\hline \multirow[t]{2}{*}{ Q3B } & $\begin{array}{l}\text { [The US should go beyond the Paris } \\
\text { Agreement and aim for more significant } \\
\text { cutbacks on greenhouse gas emissions.] }\end{array}$ & 8.5 & 4.2 & $-4.300^{\star \star \star}$ & 8.66 & 4.92 & $-3.740^{\star \star \star}$ & 0.160 & $0.720^{\star}$ & -0.560 \\
\hline & Most polarized & 10.000 & 0.0 & $-10.000^{\star \star \star}$ & 9.291 & 2.258 & $-7.033^{\star \star \star}$ & $-0.709^{*}$ & $2.258^{\star \star \star}$ & $-2.967^{\star \star \star}$ \\
\hline \multirow[t]{2}{*}{ Q3C } & $\begin{array}{l}\text { [The US should use taxes or other market } \\
\text { incentives to achieve emissions reductions.] }\end{array}$ & 8.0 & 4.2 & $-3.830^{\star * \star}$ & 8.2 & 5.19 & $-3.010^{\star \star *}$ & 0.180 & $1.000^{\star \star \star}$ & $-0.820^{\star \star}$ \\
\hline & Most polarized & 10.000 & 0.000 & $-10.000^{\star \star *}$ & 8.617 & 2.483 & $-6.134^{\star \star *}$ & $-1.383^{\star \star *}$ & $2.483^{\star \star \star}$ & $-3.866^{* * *}$ \\
\hline \multirow[t]{2}{*}{ Q3D } & $\begin{array}{l}\text { [A Green New Deal to commit to major } \\
\text { investments in infrastructure and renewable } \\
\text { energy.] }\end{array}$ & 8.1 & 3.5 & $-4.590^{\star \star \star}$ & 7.94 & 2.96 & $-4.980^{\star * *}$ & -0.140 & -0.530 & 0.390 \\
\hline & Most polarized & 10.000 & 0.000 & $-10.000^{\star \star \star}$ & 8.649 & 0.889 & $-7.760^{\star \star \star}$ & $-1.351^{\star \star *}$ & $0.889^{\star \star}$ & $-2.240^{\star \star *}$ \\
\hline \multirow[t]{2}{*}{ Q3E } & $\begin{array}{l}\text { [The US should expand oil and gas } \\
\text { production.] }\end{array}$ & 3.9 & 7.0 & $3.070^{\star * *}$ & 3.21 & 6.47 & $3.260^{\star \star \star}$ & $-0.670^{\star \star \star}$ & -0.480 & 0.190 \\
\hline & Most polarized & 0.000 & 10.000 & $10.000^{\star \star *}$ & 0.538 & 8.852 & $8.314^{\star * \star}$ & $0.538^{\star *}$ & $-1.148^{\star \star}$ & $-1.686^{\star}$ \\
\hline \multirow[t]{2}{*}{ Q3H } & $\begin{array}{l}\text { [The US should mandate zero carbon } \\
\text { emissions for cars, trucks, and buses.] }\end{array}$ & 6.9 & 3.25 & $-3.660^{\star \star \star}$ & 6.09 & 3.15 & $-2.940^{\star \star \star}$ & $-0.820^{\star \star \star}$ & -0.100 & $-0.720^{\star}$ \\
\hline & Most polarized & 10.000 & 0.000 & $-10.000^{\star \star \star}$ & 7.511 & 0.838 & $-6.673^{\star \star \star}$ & $-2.489^{\star \star \star}$ & $0.838^{*}$ & $-3.327^{\star * \star}$ \\
\hline
\end{tabular}




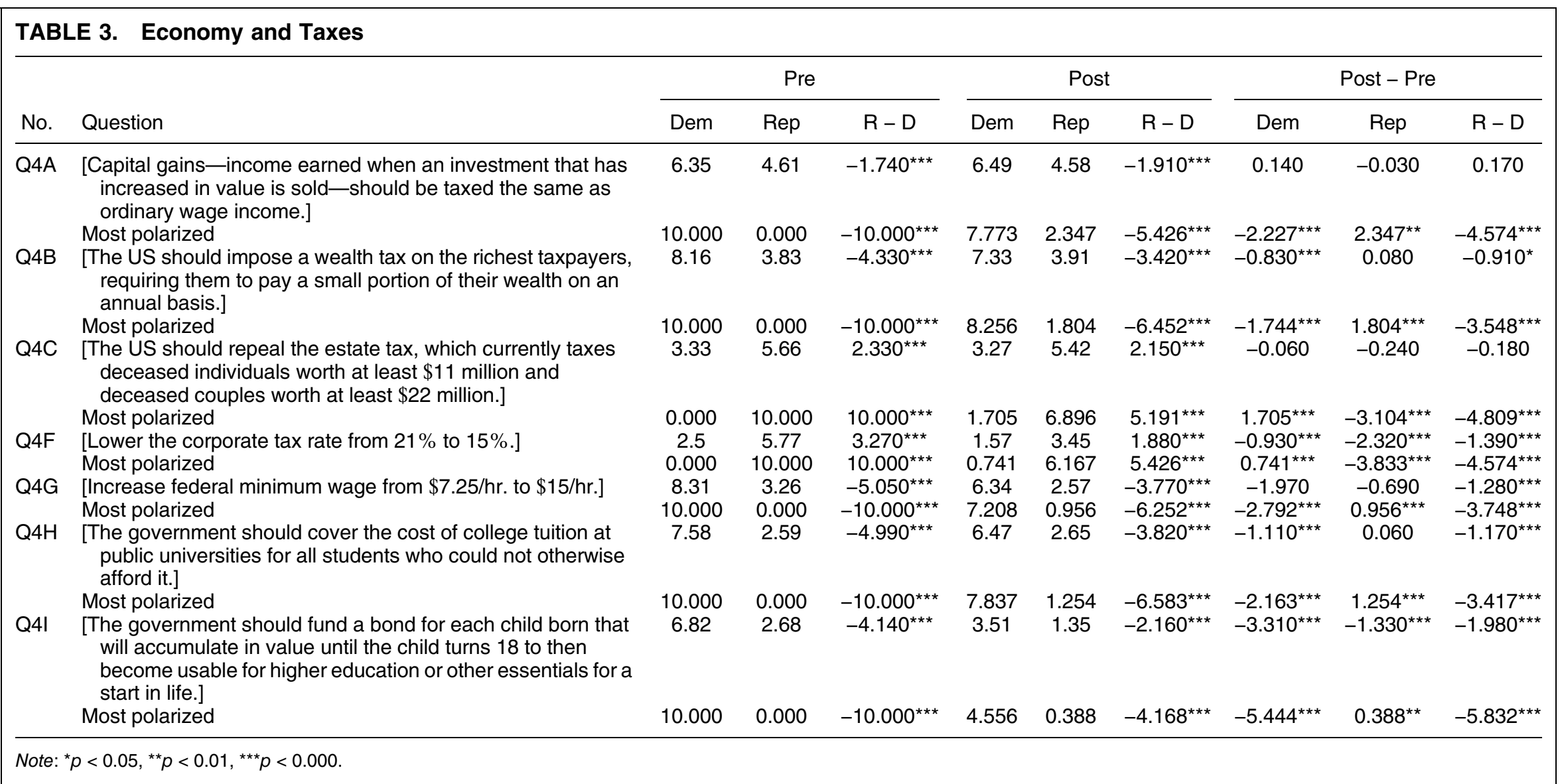




\section{TABLE 4. Health Care}

\begin{tabular}{|c|c|c|c|c|c|c|c|c|c|c|}
\hline \multirow[b]{2}{*}{ No. } & \multirow[b]{2}{*}{ Question } & \multicolumn{3}{|c|}{ Pre } & \multicolumn{3}{|c|}{ Post } & \multicolumn{3}{|c|}{ Post - Pre } \\
\hline & & Dem & Rep & $R-D$ & Dem & Rep & $R-D$ & Dem & Rep & $R-D$ \\
\hline \multirow[t]{2}{*}{ Q5A } & [The Affordable Care Act should be repealed.] & 1.87 & 7.52 & $5.650^{\star \star \star}$ & 1.84 & 5.72 & $3.880^{\star \star \star}$ & -0.030 & $-1.800^{\star \star \star}$ & $-1.770^{\star \star *}$ \\
\hline & Most polarized & 0.000 & 10.000 & $10.000^{\star \star \star}$ & 0.776 & 7.345 & $6.569^{\star \star \star}$ & $0.776^{\star \star \star}$ & $-2.655^{\star \star \star}$ & $-3.431^{\star * *}$ \\
\hline \multirow[t]{2}{*}{ Q5B } & $\begin{array}{l}\text { [Repeal the Affordable Care Act and replace } \\
\text { with grants to state Governments to create } \\
\text { their own systems.] }\end{array}$ & 2.25 & 5.62 & $3.370^{\star \star \star}$ & 2.38 & 5.03 & $2.650^{\star \star \star}$ & 0.130 & -0.590 & -0.720 \\
\hline & Most polarized & 0.000 & 10.000 & $10.000^{* \star *}$ & 1.292 & 6.739 & $5.447^{\star \star \star}$ & $1.292^{\star \star \star}$ & $-3.261^{\star \star \star}$ & $-4.553^{\star \star *}$ \\
\hline \multirow[t]{2}{*}{ Q5C } & $\begin{array}{l}\text { [The federal subsidies in the Affordable Care } \\
\text { Act that help the poor should be increased.] }\end{array}$ & 7.72 & 3.54 & $-4.180^{\star * \star}$ & 7.65 & 4.6 & $-3.050^{\star * \star}$ & -0.070 & $1.060^{\star \star \star}$ & $-1.130^{\star * *}$ \\
\hline & Most polarized & 10.000 & 0.000 & $-10.000^{\star \star \star}$ & 8.753 & 3.071 & $-5.682^{\star \star \star}$ & $-1.247^{\star \star \star}$ & $3.071^{\star \star \star}$ & $-4.318^{\star * \star}$ \\
\hline \multirow[t]{2}{*}{ Q5D } & $\begin{array}{l}\text { [The federal subsidies in the Affordable Care } \\
\text { Act that help the middle class should be } \\
\text { expanded to include more people.] }\end{array}$ & 7.86 & 4.21 & $-3.650^{\star \star \star}$ & 7.94 & 5.58 & $-2.360^{\star \star \star}$ & 0.080 & $1.370^{\star \star \star}$ & $-1.290^{\star \star \star}$ \\
\hline & Most polarized & 10.000 & 0.000 & $-10.000^{\star \star \star}$ & 8.802 & 4.292 & $-4.510^{\star \star \star}$ & $-1.198^{\star \star \star}$ & $4.292^{\star \star \star}$ & $-5.490^{\star \star \star}$ \\
\hline \multirow[t]{2}{*}{ Q5H } & $\begin{array}{l}\text { [People should be automatically enrolled in a } \\
\text { more generous version of Medicare.] }\end{array}$ & 7.39 & 3.48 & $-3.910^{\star \star \star}$ & 6.41 & 3.04 & $-3.370^{\star \star \star}$ & $-0.980^{\star \star \star}$ & -0.440 & -0.540 \\
\hline & Most polarized & 10.000 & 0.000 & $-10.000^{\star \star \star}$ & 7.758 & 1.147 & $-6.611^{\star \star \star}$ & $-2.242^{\star \star \star}$ & $1.147^{\star \star \star}$ & $-3.389^{\star \star}$ \\
\hline
\end{tabular}




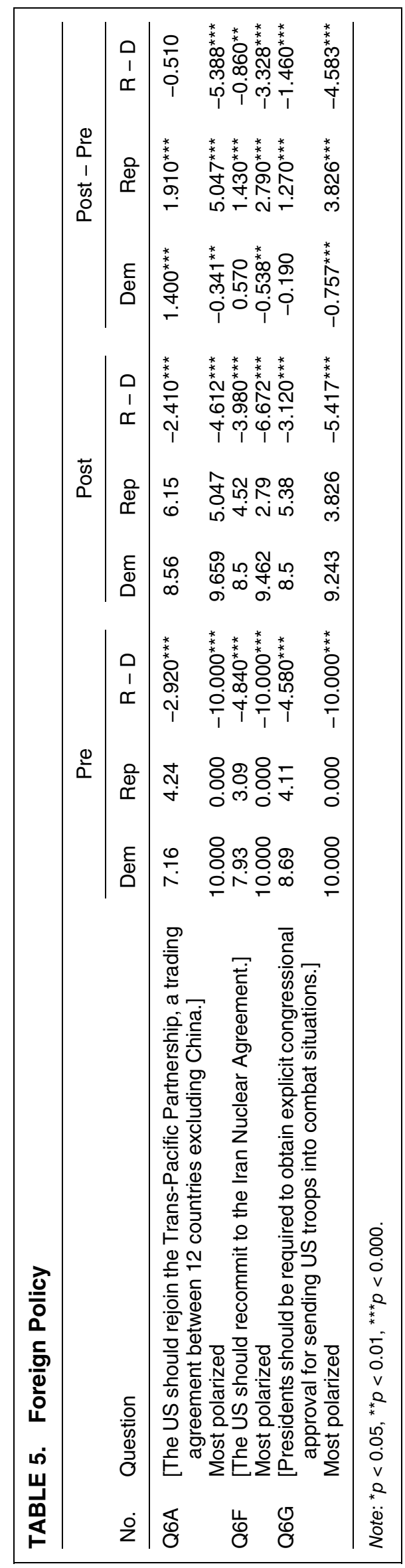

Republicans was at $79 \%$ (with a mean of 7.9). After deliberation it dropped in half to $40 \%$ (a mean of 5.32). Democratic opposition to the proposal increased with deliberation, from $63 \%$ (mean 3.3) before deliberation to $78 \%$ (mean 2.44 ) after. For partisans initially taking the strongest positions, Republican mean support dropped substantially from 10 to 6.62, whereas Democrats' opposition softened only slightly (from 0 to 0.87 ).

The sample did not have any undocumented immigrants because it included only registered voters. But many participants had family or acquaintances who were undocumented, and these perspectives were part of the discussion. While every effort was made to provide a balance of perspectives in the briefing materials and the plenary sessions, the opinions shifted markedly in a direction more sympathetic to the plight of the undocumented as well as of refugees and immigrants more generally. On all five immigration issues, Republicans and Democrats ended up significantly closer together even when the movement was mostly one-sided, as can be seen in the last column of Table 1 . In two cases, (DACA and visas for low-income workers) Republicans moved so far that they ended on the same side as the Democrats, changing from opposition to support

\section{ENVIRONMENT}

Six environmental proposals satisfied our criteria for extreme partisan polarization. These mostly focused on climate change, but energy independence was also discussed. The changes for the environment proposals can be found in Table 2. Consider "The US should commit to the 2014 Paris Agreement to combat climate change." Support among Democrats began very high and stayed high: $89 \%$ (a mean of 8.9 ) before deliberation and $91 \%$ (a mean of 9.06) after deliberation. Republicans, on the other hand, greatly decreased their opposition. They went from $56 \%$ opposed (mean of 3.7 ) to only $40 \%$ opposed (mean 4.54 ). For those taking the strongest positions on either side, Democrats' support declined slightly (from a mean of 10 to 9.61), whereas Republicans' opposition softened more substantially (from 0 to 2.27 )

Overall, three of the six polarized issues on the environment saw two-sided depolarization, as documented in the last column in Table 2. In addition, the proposal for "Moving beyond the Paris agreement" experienced one-sided depolarization. Finally, all six of the proposals showed two-sided depolarization among those beginning with the most polarized positions.

\section{THE ECONOMY AND TAXES}

Seven economic proposals exhibited extreme partisan polarization. Several of these were progressive proposals that lost support from the Democrats after deliberation. Democrats expressed concerns about the expense of some proposals in light of the national 
debt and they also moved in response to geographically diverse concerns about imposing a national policy (like a $\$ 15$ minimum wage) that did not account for local variation.

The most dramatic drop was on "The government should fund a bond for each child born that will accumulate in value until the child turns 18 to then become usable for higher education or other essentials for a start in life." This so-called "Baby Bonds" proposal was a centerpiece in the campaign of a Democratic presidential candidate. ${ }^{6}$

The Baby Bonds proposal was initially supported by $62 \%$ of Democrats (mean 6.82), but this support plummeted by two thirds to $21 \%$ after deliberation (mean $3.51)$. Republican support started low $(15 \%$, mean of $2.68)$ and dropped lower (5\%, mean of 1.35). Even Democrats who took the strongest position declined sharply in support (from a mean of 10 to 4.56). Republicans who took the strongest position barely warmed in their opposition (from 0 to 0.39 ).

Another ambitious proposal was to "increase the federal minimum wage from $\$ 7.25$ an hour to $\$ 15 /$ hour." Democratic support for this proposal dropped 23 points from $82 \%$ (mean of 8.31 ) to $59 \%$ (mean of 6.34). Republican opposition increased from $63 \%$ (mean of 3.26 ) to $71 \%$ (mean of 2.57). While Republican opposition increased, Democratic support dropped much more. Thus, Republicans and Democrats ended up closer together. As for those taking the strongest positions, Democrats who started out at 10 in support went down substantially to a mean of 7.21. Republicans who started out at 0 in opposition went up only slightly to 0.96 .

Of the seven economic proposals, five produced twosided depolarization between Republicans and Democrats. Among those starting with the strongest positions, all seven proposals showed two-sided depolarization.

\section{HEALTH CARE}

Five health care proposals fit the criteria for extreme partisan polarization. Some were strongly supported by Republicans (and opposed by Democrats) and others strongly supported by Democrats (and opposed by Republicans). Consider "The Affordable Care Act should be repealed." Support for this proposal to eliminate "Obamacare" was initially at $69 \%$ among Republicans (mean of 7.52). After deliberation, it dropped 21 points among Republicans to $48 \%$ (mean of 5.72). Democrats were strongly opposed both before and after ( $76 \%$ opposed, mean of 1.87 before deliberation; $80 \%$ opposed, mean of 1.84 afterwards). Republicans taking the strongest position in support moved much more, from a mean of 10 to 7.35 . Democrats taking the strongest position in opposition moved only slightly, from 0 to 0.78 . Before deliberation, $48 \%$ of

\footnotetext{
${ }^{6}$ Senator Cory Booker. However, proposals were not identified with candidates (or parties) but presented in the briefings in nonpartisan terms so that participants could consider them on the merits.
}

Republicans took the strongest position in support of eliminating the ACA, whereas after, only $22 \%$ did. Before deliberation, $58 \%$ of Democrats took the strongest position in opposition to this proposal; afterwards it dropped to $50 \%$.

Consider now a Democratic-leaning health care proposal, "Medicare for All": that "People should be automatically enrolled in a more generous version of Medicare." This started high among Democrats (70\% support, mean of 7.39), but dropped 14 points to $56 \%$ after deliberation (mean of 6.41). Republicans opposed this both before and after ( $63 \%$ to $66 \%$, mean of 3.04$)$. Democrats who initially took the strongest position in favor moderated their views appreciably, going from a mean of 10 to 7.76. Republicans who took the strongest position in opposition moderated a bit, from 0 to 1.147.

Of the five polarized proposals on health care, three showed two-sided and one (Medicare for All) showed one-sided depolarization. In that case, the Democrats moved in a more moderate direction toward the midpoint but the Republicans did not.

\section{FOREIGN POLICY}

Only three foreign policy proposals fit our criteria for extreme partisan polarization. The two most contentious were the Iran Nuclear Agreement and the TransPacific Partnership (TPP).

On "The US should recommit to the Iran Nuclear Agreement," Republican opposition dropped by a third, from $63 \%$ (mean of 3.09 ) to $41 \%$ (mean of 4.52). Democratic support increased slightly from $78 \%$ (mean of 7.93 ) to $83 \%$ (mean of 8.5 ). For those with the strongest views on the scale, Republican opposition decreased a lot, from a mean of 0 to 2.79 , whereas Democratic support decreased only slightly, from 10 to 9.46 .

On the proposal "The US should rejoin the TransPacific Partnership, a trading agreement between 12 countries excluding China," Democrats started high (66\% with a mean of 7.16$)$ and went dramatically higher $(88 \%$ with a mean of 8.56$)$. In other words, Democratic support increased by a third. Meanwhile, Republicans rose even more dramatically from $23 \%$ (mean of 4.24) to 62\% (mean of 6.15), an increase of 39 points. Republicans transformed from a mean position of opposition to one of support. This was thus a classic instance in which the depolarizing effect of deliberation resulted in both sets of partisans supporting the same policy. Democrats who took the strongest possible position in support declined only slightly (from 10 to 9.66). Republicans who took the strongest possible position in opposition flipped over the midpoint (going from 0 to 5.05) - one of the two biggest changes in average support among the strongest advocates of any position in our Deliberative Poll. ${ }^{7}$ Opposition to

\footnotetext{
${ }^{7}$ The "baby bonds" proposal produced a comparable drop in average support (5.44) among the Democrats initially taking the strongest position.
} 
TABLE 6. Issue-Based Depolarization

\begin{tabular}{lccccc}
\hline & $\begin{array}{c}\text { One-sided } \\
\text { depolarization }\end{array}$ & $\begin{array}{c}\text { Two-sided } \\
\text { depolarization }\end{array}$ & $\begin{array}{c}\text { R \& D } \\
\text { become } \\
\text { closer }\end{array}$ & $\begin{array}{c}\text { R \& D become } \\
\text { significantly closer (or } \\
\text { move to same side) }\end{array}$ & $\begin{array}{c}\text { R \& D become significantly } \\
\text { closer compared with } \\
\text { movements in control group }\end{array}$ \\
\hline $\begin{array}{c}\text { Party members } \\
\begin{array}{c}\text { Overall } \\
\text { Most polarized }\end{array}\end{array}$ & 21 & 5 & 22 & 19 & 20 \\
\hline
\end{tabular}

TABLE 7. Affective Polarization

\begin{tabular}{|c|c|c|c|c|c|c|c|c|c|c|}
\hline \multirow[b]{2}{*}{ Democrats } & \multicolumn{4}{|c|}{ Participants } & \multicolumn{4}{|c|}{ Control } & \multirow{2}{*}{$\begin{array}{c}(\mathrm{P} \text { T2 }-\mathrm{T} 1)- \\
(\mathrm{C} \mathrm{T} 2-\mathrm{T} 1)\end{array}$} & \multirow[b]{2}{*}{ Sig. } \\
\hline & $\mathrm{T} 1$ & $\mathrm{~T} 2$ & $\mathrm{~T} 2-\mathrm{T} 1$ & Sig. & $\mathrm{T} 1$ & T2 & $\mathrm{T} 2-\mathrm{T} 1$ & Sig. & & \\
\hline Own party & 71.35 & 73.91 & 2.56 & 0.035 & 70.13 & 69.33 & -0.80 & 0.302 & 3.36 & 0.030 \\
\hline Other party & 19.49 & 32.56 & 13.07 & 0.000 & 21.75 & 21.06 & -0.69 & 0.551 & 13.76 & 0.000 \\
\hline $\begin{array}{l}\text { Affective } \\
\text { polarization } \\
\text { measure }\end{array}$ & 52.11 & 41.22 & -10.89 & 0.000 & 48.71 & 47.92 & -0.79 & 0.652 & -10.10 & 0.000 \\
\hline Republicans & $\mathrm{T} 1$ & $\mathrm{~T} 2$ & $\mathrm{~T} 2-\mathrm{T} 1$ & Sig. & $\mathrm{T} 1$ & $\mathrm{~T} 2$ & $\mathrm{~T} 2-\mathrm{T} 1$ & Sig. & $\begin{array}{l}(\mathrm{P} \text { T2 }-\mathrm{T} 1)- \\
\quad(\mathrm{C} \text { T2 - T1) }\end{array}$ & Sig. \\
\hline Own party & 67.28 & 65.84 & -1.44 & 0.409 & 71.47 & 71.00 & -0.47 & 0.645 & -0.97 & 0.608 \\
\hline Other party & 20.16 & 34.63 & 14.47 & 0.000 & 19.47 & 19.05 & -0.42 & 0.712 & 14.89 & 0.000 \\
\hline $\begin{array}{l}\text { Affective } \\
\text { polarization } \\
\text { measure }\end{array}$ & 46.97 & 31.19 & -15.78 & 0.000 & 51.44 & 51.04 & -0.39 & 0.791 & -15.39 & 0.000 \\
\hline
\end{tabular}

the TPP collapsed with deliberation, and support for international cooperation on this and other items increased dramatically. While the gap between Republicans and Democrats on the scale decreased, the change was not statistically significant because as Republicans moved from opposition to support, Democrats moved to even stronger support. Since Republicans changed sides on this issue, it was two-sided depolarization as noted earlier.

\section{OVERVIEW OF ISSUE-BASED RESULTS}

Overall, there were 26 proposals that fit our criteria for partisan-based polarization. Table 6 provides a simple scorecard of results for the effect of deliberation.

Republican and Democratic partisans moved closer on 22 out of the 26 proposals. In 19, the movements were statistically significant. ${ }^{8}$ The 19 includes one case, the TPP, where the decline in distance between Republicans and Democrats was not significant, but only because the two parties ended up on the same side of the issue after each moved to statistically significant degrees. Republicans moved or depolarized so much that they crossed the midpoint to the same side as the Democrats, and 21 of the 26 items showed depolariza-

\footnotetext{
${ }^{8}$ Significance at least at the 0.05 level with two-tailed tests.
}

tion by one party and not the other. As noted earlier, both parties showed some equally large movements in a depolarizing direction. ${ }^{9}$

Among partisans of each party who initially took the strongest possible positions, in either support or opposition, there was two-sided depolarization on all 26 highly polarized proposals. When difference-in-difference analyses are included, 20 out of the 26 proposals are significant for partisans ${ }^{10}$ and 26 out of 26 proposals remain significant for those starting at the polar ends of the scale (see the online appendix for the difference in difference analyses). These results support both hypotheses 1 and 2 .

\section{AFFECTIVE POLARIZATION}

Whether deliberation influences affective polarization is a separate question. The dynamics of the two kinds of polarization are distinguishable (Iyengar et al. 2019). H3 hypothesized that with an appropriate design, deliberation between members of different parties will reduce affective polarization. We argued that the Deliberative Polling design satisfies the four criteria

\footnotetext{
${ }^{9}$ Table A7 in the online Appendix shows the contrasting results for the 21 nonpolarized items. In only five cases did they move significantly closer together.

${ }^{10}$ This count includes the TPP question because the two parties moved to the same side.
} 
TABLE 8. Extremity and Democrats' Feelings toward Republicans

\begin{tabular}{|c|c|c|c|c|}
\hline $\begin{array}{l}\text { \# of polarized questions where respondents give } \\
\text { extreme answers at T1 }\end{array}$ & $N$ & $\begin{array}{l}\text { T1 Feelings Toward } \\
\text { other party mean }\end{array}$ & $\begin{array}{l}\text { T2 Feelings Toward } \\
\text { other party mean }\end{array}$ & $\mathrm{T} 2-\mathrm{T} 1$ \\
\hline None & 13 & 37 & 40 & +3 \\
\hline $1-5$ & 37 & 27 & 37 & $+10^{\star}$ \\
\hline $6-10$ & 44 & 23 & 36 & $+13^{\star *}$ \\
\hline $11-15$ & 46 & 14 & 30 & $+16^{\star \star \star}$ \\
\hline $16-26$ & 38 & 8 & 24 & $+16^{\star \star \star}$ \\
\hline
\end{tabular}

Note: Higher Score $=$ Warmer Feeling; ${ }^{\star} p<0.05,{ }^{\star \star} p<0.01,{ }^{\star \star \star} p<0.000$; two-tailed test.

\section{TABLE 9. Extremity and Republicans' Feelings toward Democrats}

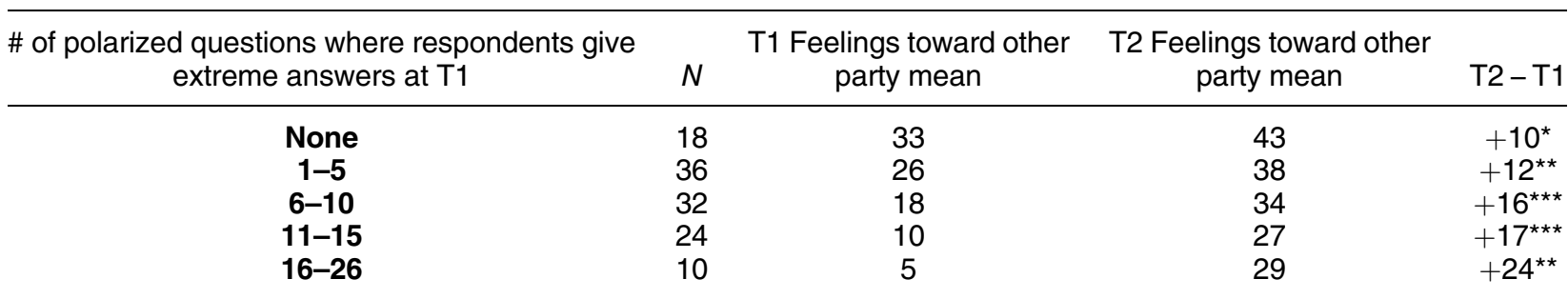

Note: Higher Score $=$ Warmer Feeling; ${ }^{*} p<0.05,{ }^{\star *} p<0.01,{ }^{\star * \star} p<0.000$; two-tailed test.

originally put forward by Allport and later supported by meta-analyses (Allport 1954; Pettigrew and Tropp 2006). Therefore, the contact hypothesis would support a reduction in affective polarization. Table 7 shows what happened for party members in general.

Affective polarization can be measured in at least two ways: thermometer ratings for the other party and the difference in thermometer ratings for one's own party minus the other party (Iyengar et al. 2019). Both measures are pictured in Table 7 and the results are essentially the same. Partisans exhibited little change in their ratings of their own party but large and significant changes in their ratings of the other party. Democrats' thermometer ratings of Republicans rose 13 points with deliberation. Republicans' thermometer ratings of Democrats rose 14 points. As pictured in the table, the thermometer ratings for the control group were essentially unchanged. On either measure, our results support $\mathrm{H} 3$ for party members overall. These are large and significant effects by the standards of other experiments at depolarization (see Levendusky 2018 for some imaginative efforts).

What about affective polarization among those starting out with the most polarized views on the issues? Tables 8 and 9 show a stunning effect. The more often (across our 26 polarized issues) that partisans (both Democrats and Republicans) chose the extreme position ( 0 or 10$)$ on the scale, the larger was the reduction in their affective polarization after deliberation. Democrats who chose the maximum position (for or against) on 11 or more of the 26 polarized questions increased their feeling thermometer toward Republicans by an average of 16 points. Republicans who offered extreme answers to 11 or more polarized questions increased their feeling thermometer toward Democrats by at least 17 points on average (and among the most frequent Republican maximalists, the average improvement in feeling toward Democrats was 24 points).

In other words, the more extreme were respondents' issue positions before deliberation, the more their thermometer ratings toward members of the other party rose with deliberation. Thus, the contact hypothesis seemed to work, not just for party members in general but for members of each party who took the strongest positions before deliberation. These results support H4. By way of explanation, we speculate that those who took the most extreme issue positions on the scale at time 1, whether Republicans or Democrats, may have been even more isolated from serious contact with the other side than were party members in general.

\section{CONCLUSION}

These results from a national field experiment offer proof of concept that deliberation, with an appropriate design, can dramatically narrow differences between Republicans and Democrats on issues where they are initially deeply polarized. The Deliberative Poll seems to be at least one design that does this. Added research will show if there are others. ${ }^{11}$

\footnotetext{
${ }^{11}$ Are the effects lasting? The answer is both no and yes. We focus on long-term effects in a separate paper. On the basis of follow-up waves with both the treatment and control groups, we see that some effects dissipate but others, such as voting intention near the time of the election more than a year later, show dramatic differences between the treatment and control group.
} 
A critic might say that while this field experiment shows that the deliberative process can have a major effect, the effect is limited to so few people that it is hardly of any use. Can participation in such an organized design be scaled to larger populations? Dealing with the dual challenge of substantive and affective polarization would require many people outside the random sample to depolarize.

This limitation should be a prod to innovation. We can foster opportunities for many more people to deliberate. There is now a global community of researchers and practitioners experimenting with deliberative democracy (for a comprehensive compendium see Bächtiger et al. 2018). Recent experiments have already productively introduced deliberative designs into the schools as a form of civic education ${ }^{12}$ and engaged minipublics in local public policy consultations. Deliberative designs have also been used for meetings between the public and elected representatives (Neblo, Esterling, and Lazer 2018), for televising deliberations on key national issues, and for experimenting with the effect of exposure (via television or print) to the results of deliberating minipublics (Már and Gastil 2019; Rasinski, Bradburn, and Lauen 1999). Because of its cost effectiveness (foregoing the need to pay for transportation and hotels), online deliberation with video-based discussions enables a dramatic increase in the number of deliberating participants. Large numbers of video-based small group discussions can now be accommodated by an automated moderator, with a design to foster balanced, thoughtful discussion comparable to a Deliberative Poll (Fishkin et al. 2019).

This technologically enlarged deliberation could be part of a wider-scale Deliberative Poll or a method of realizing the idea of Deliberation Day, a proposal to have very large numbers of small group discussions convened before a national election (Ackerman and Fishkin 2004). Such a design realizes components of a "deliberative system" (Mansbridge et al. 2012), to help exert more deliberative popular control (Fishkin 2018, 199-210). What seems utopian in the form of face-toface discussion (because of the prohibitive cost of bringing people physically together) might be made practical online. If the essential treatment is moderated, mutually respectful discussion among diverse others of competing arguments, supported by balanced information, then there is no need for the participants to be drawn in a random sample, so long as they are recruited at scale and assigned by algorithms to ensure diversity in each small group. Such wider-scale discussions would not be intended to represent the overall population, but they might help create a more thoughtful and substantive form of public opinion when brought to scale.

We can speculate more broadly. If deliberation supports accuracy-based rather than partisan-motivated reasoning and if it defuses affective polarization (via

\footnotetext{
${ }^{12}$ See, for example, https://cdd.stanford.edu/2016/deliberativepolling-for-summit-public-schools/.
}

the contact hypothesis), then it would likely lessen receptiveness to partisan-motivated falsehoods. The sustained close interaction among diverse participants seems to open people's minds and hearts, defusing the motivation to cling to falsehoods.

Our results suggest that the challenge now is to create a more-deliberative society, if aspirations for lesspolarized public opinion and more mutually respectful citizenship are to be realized. We need more institutions that encourage evidence-based, thoughtful public discussion across our deep divisions. If one imagines "America in One Room" not as a minipublic but as an image of what needs to be brought to scale, one sees the potential for a deeper and more thoughtful democracy. Deliberation can engage citizens in choices that are based on more than partisan conformity, one-sided argumentation, or a mere impression of sound bites and headlines. Our findings suggest it is possible, at the level of mass public opinion, to build a democracy that transcends partisan deadlock. This field experiment is a pilot for imagining democratic possibilities.

\section{SUPPLEMENTARY MATERIALS}

To view supplementary material for this article, please visit http://dx.doi.org/10.1017/S0003055421000642.

\section{DATA AVAILABILITY STATEMENT}

Research documentation and data that support the findings of this study are openly available at the American Political Science Review Dataverse: https://doi. org/10.7910/DVN/KJ8IH2.

\section{ACKNOWLEDGMENTS}

Earlier versions of this paper were presented at the 2020 meetings of the American Association for Public Opinion Research and the 2020 meetings of the American Political Science Association. We would especially like to thank Henry Elkus and Sam Feinburg of Helena for their vision and collaboration. Michael Dennis, Jessica Carter, and their superb team at NORC at the University of Chicago were essential. Valentin Bolotnyy and Joshua Lerner offered insightful comments. Bruce Ackerman was especially noteworthy in helping to conceptualize the initial work. Dan Werner of "By the People Productions" played an essential role in executing the project. We would also like to acknowledge the support of the Helena Group Foundation and the advice and counsel of the distinguished Advisory Committee for America in One Room: Alexandra Rojas, Ben Ginsberg, Bill Galston, Bob Shrum, Bruce Ackerman, Eleanor Smeal, Irasema Coronado, Jane Mansbridge, Katherine Spillar, Kristen Clarke, Lanhee Chen, Luis Fraga, Norman Bradburn, Pete Peterson, and Peter Goldmark - and special thanks to research 
assistants: Erica Turret, Robbie Flatow, Caleb Young, Cornell Overfield, and Hannah Abelow.

\section{FUNDING STATEMENT}

This research was funded by the Helena Group Foundation.

\section{CONFLICT OF INTEREST}

The authors declare no ethical issues or conflicts of interest in this research.

\section{ETHICAL STANDARDS}

The authors declare that the human subjects research in this article was reviewed and approved by NORC at the University of Chicago and certificate numbers are provided in the appendix. The authors also affirm that this article adheres to the APSA's Principles and Guidance on Human Subject Research.

\section{REFERENCES}

Abramowitz, Alan I. 2013. The Polarized Public? Why American Government is so Dysfunctional. New York: Pearson.

Abramowitz, Alan I. 2018. The Great Alignment: Race, Party Transformation, and the Rise of Donald Trump. New Haven, CT: Yale University Press.

Ackerman, Bruce. 1993. We the People, Volume 1: Foundations. Cambridge, MA: Harvard University Press.

Ackerman, Bruce, and James Fishkin. 2004. Deliberation Day. New Haven, CT: Yale University Press.

Andersen, Ida-Elisabeth, and Birgit Jaeger. 1999. "Scenario Workshops and Consensus Conferences: Towards More Democratic Decision-Making." Science and Public Policy 26 (5): 331-40.

Allport, Gordon W. 1954. The Nature of Prejudice. New York: Perseus Books.

Asch, Solomon E. 1955. "Opinions and Social Pressure." Scientific American 193 (5): 31-5.

Bächtiger, Andre, John S. Dryzek, Jane Mansbridge, and Mark E. Warren. 2018. The Oxford Handbook of Deliberative Democracy. Oxford: Oxford University Press.

Barabas, Jason. 2004. "How Deliberation Affects Policy Opinions." The American Political Science Review 98 (4): 687-701.

Berry, Jeffrey M., and Sarah Sobieraj. 2014. The Outrage Industry. Oxford: Oxford University Press.

Bessette, Joseph M. 1994 The Mild Voice of Reason: Deliberative Democracy and American National Government. Chicago: University of Chicago Press.

Boatright, Robert G. 2014. Getting Primaried: The Changing Politics of Congressional Primary Challenges. Ann Arbor: University of Michigan Press.

Burke, Edmund. [1774] 1854. "Speech to the Electors of Bristol." Reprinted in Vol 1, The Works of the Right Honourable Edmund Burke, 6 vols, 446-48. London: Henry G. Bohn.

Campbell, James E. 2016. Polarized: Making Sense of a Divided America. Princeton, NJ: Princeton University Press.

Chirawurah, Dennis, James Fishkin, Niagia Santuah, Alice Siu, Ayaga Bawah, Gordana Kranjac-Berisavljevic, and Kathleen Giles. 2019. "Deliberation for Development: Ghana's First Deliberative Poll." Journal of Public Deliberation 15 (1): Article 3.

Chong, Dennis, and James Druckman. 2007. "Framing Public Opinion in Competitive Democracies." The American Political Science Review 101 (4): 637-55.
Conover, Pamela Johnston, Donald D. Searing, and Ivor M. Crewe. 2002. "The Deliberative Potential of Political Discussion." British Journal of Political Science 32 (1): 21-62.

Delli Carpini, Michael, and Scott Keeter. 1996. What Americans Know about Politics and Why it Matters. New Haven, CT: Yale University Press.

Dennis, J. Michael, Jennifer Carter, Caroline Tipler, Mark Watts, and Y. Michael Yang. 2020. "Bringing a Representative Sample of Voters to 'America in One Room': Sampling \& Recruitment." Paper Presented at the meetings of the American Association of Public Opinion Research. https://cdd.stanford.edu/ mm/2020/07/Dennis_AAPOR_A1R_SamplingRecruitment.pdf.

Downs, Anthony. 1957. An Economic Theory of Democracy. New York: Harper and Row.

Druckman, James N. 2012. "The Politics Of Motivation." Critical Review 24 (2): 199-216.

Farrar, Cynthia, James Fishkin, Don Green, Christian List, Robert C. Luskin, and Elizabeth Levy Paluck. 2010. "Disaggregating Deliberation's Effects." British Journal of Political Science 40 (2): 333-47.

Farrell, David M., Jane Suiter, and Clodagh Harris. 2018. “'Systematizing' Constitutional Deliberation: The 2016-18 Citizens' Assembly in Ireland." Irish Political Studies 34 (1): 113-23.

Farrell, David M., Jane Suiter, Clodagh Harris, and Kevin Cunningham. 2019. "The Effects of Mixed Membership in a Deliberative Forum: The Irish Constitutional Convention of 2012-2014." Political Studies 68 (1): 54-73.

Fiorina, Morris P., with Samuel J. Abrams. 2009. Disconnect: The Breakdown of Representation in American Politics. Norman: University of Oklahoma Press.

Fiorina, Morris P. 2017. Unstable Majorities: Polarization, Party Sorting and Political Stalemate. Stanford, CA: Hoover Institution Press.

Fishkin, James. 2018. Democracy When the People Are Thinking. Oxford: Oxford University Press.

Fishkin, James S., and Mansbridge, Jane. 2017. "Introduction." Daedalus 146 (3): 6-13.

Fishkin, James S., Alice Siu, Larry Diamond, and Norman Bradburn. 2021. "Replication Data for: Is Deliberation an Antidote to Extreme Partisan Polarization? Reflections on 'America in One Room."” Harvard Dataverse. Dataset. https://doi.org/10.7910/ DVN/KJ8IH2.

Fishkin, James, Nikhil Garg, Lodewijk Gelauff, Ashish Goel, Kamesh Munagala, Sukolsak Sakshuwong, Alice Siu, and Sravya Yandamuri. 2019. "Deliberative Democracy with the Online Deliberation Platform." The 7th AAAI Conference on Human Computation and Crowdsourcing (HCOMP 2019): 1-2. https:// www.humancomputation.com/2019/assets/papers/144.pdf.

Fournier, Patrick, Henk van der Kolk, R. Kenneth Carty, André Blais, and Jonathan Rose. 2011. When Citizens Decide: Lessons from Citizen Assemblies on Electoral Reform. Oxford: Oxford University Press.

Goodin, Robert E. 2003. "Democratic Deliberation Within.” In Debating Deliberative Democracy, eds. James Fishkin and Peter Laslett, 54-79. Oxford: Basil Blackwell.

Goidel, Robert K., and Todd G. Shields. 1994. "The Vanishing Marginals, the Bandwagon, and the Mass Media." The Journal of Politics 56 (3): 802-10.

Grönlund Kimmo, Kaisa Herne, and Maija Setälä. 2015. "Does Enclave Deliberation Polarize Opinions?" Political Behavior 37: 995-1020.

Hansen, Mogens Herman. 1991. The Athenian Democracy in the Age of Demosthenes. Oxford: Blackwell.

He, Baogang, and Mark E. Warren. 2011. "Authoritarian Deliberation: The Deliberative Turn in Chinese Political Development." Perspectives on Politics 9 (2): 269-89.

Hetherington, Marc J., and Thomas Rudolph. 2015. Why Washington Won't Work: Polarization, Political Trust and the Governing Crisis. Chicago: University of Chicago Press.

Hewstone, Miles, and Hermann Swart. 2011. "Fifty-Odd Years of Inter-Group Contact: From Hypothesis to Integrated Theory." British Journal of Social Psychology 50 (3): 374-86.

Hopkins, Daniel J., and John Sides eds. 2015. Political Polarization in American Politics. New York: Bloomsbury Academic.

Huckfeldt, Robert, Jeanette Morehouse Mendez, and Tracy Osborn. 2004. "Disagreement, Ambivalence, and Engagement: The 
Political Consequences of Heterogeneous Networks." Political Psychology 25 (1): 65-95.

Iyengar, Shanto, Gaurav Sood, and Yptach Lelkes. 2012. "Affect, Not Ideology: A Social Identity Perspective on Polarization." Public Opinion Quarterly 76 (3): 405-31.

Iyengar, Shanto, and Masha Krupenkin. 2018. "The Strengthening of Partisan Affect." Political Psychology 39 (S1): 201-18.

Iyengar, Shanto, Yptach Lelkes, Mathew Levendusky, Neil Malhotra, and Sean Westwood. 2019. "The Origins and Consequences of Affective Polarization in the United States." Annual Review of Political Science 22: 129-46.

Jacobs, Lawrence R., and Robert Y. Shapiro. 2000. Politicians Don't Pander: Political Manipulation and the Loss of Democratic Responsiveness. Chicago: University of Chicago Press.

Kim, Nuri, James Fishkin, and Robert C. Luskin. 2018. "Intergroup Contact in Deliberative Contexts: Evidence from Deliberative Polls.” Journal of Communication 68 (6): 1029-51.

Kunda, Ziva. 1990. "The Case for Motivated Reasoning." Psychological Bulletin 108 (3): 480-98.

Landemore, Helene. 2013. Democratic Reason. Princeton, NJ: Princeton University Press.

Lenz, Gabriel S. 2012. Follow the Leader: How Voters Respond to Politicians' Policies and Performance. Chicago: University of Chicago Press.

Leeper, Thomas J., and Rune Slothuus. 2014. "Political Parties, Motivated Reasoning, and Public Opinion Formation.” Political Psychology 35: 129-56.

Levendusky, Matthew S. 2018. "Americans, Not Partisans: Can Priming American National Identity Reduce Affective Polarization?" The Journal of Politics 80 (1): 59-70.

Levendusky, Matthew S., James N. Druckman, and Audrey Mclain. 2016. "How Group Discussions Create Strong Attitudes and Strong Partisans." Research \& Politics 3 (2): 1-6.

Lupia, Arthur. 1994. "Shortcuts versus Encyclopedias: Information and Voting Behavior in California Insurance Reform Elections." American Political Science Review 88 (1): 63-76.

Luskin, Robert C., Ian O’Flynn, James Fishkin, and David Russell. 2014. "Deliberating across Deep Divides." Political Studies 62: $116-35$.

Manin, Bernard. 1997. The Principles of Representative Government. Cambridge: Cambridge University Press.

Mansbridge, Jane. 1999. "Everyday Talk in the Deliberative System." In Deliberative Politics: Essays on Democracy and Disagreement, ed. Stephen Macedo, 211-42. Oxford: Oxford University Press.

Mansbridge, Jane, James Bohman, Simone Chambers, Thomas Christiano, Archon Fung, John Parkinson, Dennis F. Thompson, et al. 2012. "A Systemic Approach to Deliberative Democracy." In Deliberative Systems, eds. John Parkinson and Jane Mansbridge, 1-26. Cambridge: Cambridge University Press.

Maoz, Ifat. 2000. "An Experiment in Peace: Reconciliation-Aimed Workshops of Jewish-Israeli and Palestinian Youth." Journal of Peace Research 37 (6): 721-36.

Már, Kristinn, and John Gastil. 2019. "Tracing the Boundaries of Motivated Reasoning: How Deliberative Minipublics Can Improve Voter Knowledge." Political Psychology 41 (1): 107-27.

Mason, Lilliana. 2014. "'I Disrespectfully Agree': The Differential Effects of Partisan Sorting on Social and Issue Polarization." American Journal of Political Science 59 (1): 128-145.

Mill, John Stuart. [1859] 1962. On Liberty. London: John Parker and Son; reprinted New York: New American Library.

Mutz, Diana C. 2002. "Cross-Cutting Social Networks: Testing Democratic Theory in Practice." American Political Science Review 96 (1): 111-26.

Mutz, Diana C. 2015. In-Your-Face Politics: The Consequences of Uncivil Media. Princeton, NJ: Princeton University Press.
Neblo, Michael A., Kevin M. Esterling, Ryan P. Kennedy, David M. J. Lazer, and Anand E. Sokhey. 2010. "Who Wants To DeliberateAnd Why?" American Political Science Review 104 (3): 566-83.

Neblo, Michael A., Kevin M. Esterling, and David M. J. Lazer. 2018. Politics with the People: Building a Directly Representative Democracy. Cambridge: Cambridge University Press.

Noelle-Neumann, Elisabeth. 1984. "The Spiral of Silence: A Theory of Public Opinion." Journal of Communication 24 (2): 43-51.

Nyhan, Brendan, and Jason Reifler. 2010. "When Corrections Fail: The Persistence of Political Misperceptions." Political Behavior 32 (2): 303-30.

Ober, Josiah. 2008. Democracy and Knowledge: Innovation and Learning in Classical Athens. Princeton, NJ: Princeton University Press.

Page, Benjamin, and Robert Shapiro. 1992. The Rational Public: Fifty Years of Trends in Americans' Policy Preferences. Chicago: University of Chicago Press.

Pariser, Eli. 2011. The Filter Bubble. New York: The Penguin Group.

Pettigrew, Thomas F., and Linda R. Tropp. 2006. "A Meta-Analytic Test of Intergroup Contact Theory." Journal of Personality and Social Psychology 90 (5): 751-83.

Pettigrew, Thomas F., and Linda R. Tropp. 2011. When Groups Meet: The Dynamics of Intergroup Contact. New York: Psychology Press.

Petty, Richard E., and Jon A. Krosnick. 1995. Attitude Strength: Antecedents and Consequences. Mahwah, NJ: Lawrence Erlbaum Associates.

Popkin, Samuel L. 1991. The Reasoning Voter: Communication and Persuasion in Presidential Campaign. Chicago: University of Chicago Press.

Rasinski, K.A., N. M. Bradburn, and D. Lauen. 1999. "The Effects of Media Coverage of the National Issues Convention on Citizen Attitudes and Opinions." Chap. 8 in The Poll with a Human Face: National Issues Convention Experiment in Political Communications, eds. Maxwell McCombs and Amy Reynolds. Mahwah, NJ: Lawrence Erlbaum Associates.

Rosenfeld, Michael J. 2017. "Moving a Mountain: The Extraordinary Trajectory of Same-Sex Marriage Approval in the United States." Socius: Sociological Research for a Dynamic World 3: $1-22$.

Sandefur, Justin, Nancy Birdsall, James S. Fishkin, and Mujubo Moyo. 2020. "Deliberative Democracy and the Resource Curse: A National Experiment in Tanzania." Working Paper. https:// cdd.stanford.edu/mm/2020/10/sandefur-cgdev-tanzania.pdf.

Siu, Alice, and Dragan Stanisevski. 2012. "Deliberation in Multicultural Societies: Addressing Inequality, Exclusion and Marginalization." Chap. 5 in Democracy in Motion: Evaluating the Practice and Impact of Deliberative Civic Engagement, eds. Tina Nabatchi, John Gastil, G. Michael Weiksner, and Matt Leighninger. Oxford: Oxford University Press.

Sunstein, Cass R. 2002 "The Law of Group Polarization" The Journal of Political Philosophy 10 (2): 175-95.

Sunstein, Cass R. 2009. Going to Extremes: How Like Minds Unite and Divide. Oxford: Oxford University Press.

Sunstein, Cass R. 2017. \#Republic: Divided Democracy in the Age of Social Media. Princeton, NJ: Princeton University Press.

Taber, Charles S., and Milton Lodge. 2006. "Motivated Skepticism in the Evaluation of Political Beliefs." American Journal of Political Science 50 (3): 755-69.

Tajfel, Henri. 1981. Human Groups and Social Categories: Studies in Social Psychology. Cambridge: Cambridge University Press.

Warren, Mark E., and Hilary Pearse eds. 2008. Designing Deliberative Democracy: The British Columbia Citizens Assembly. Cambridge: Cambridge University Press.

Wojcieszak, Magdalena. 2011. "Deliberation and Attitude Polarization.” Journal of Communication 61 (4): 596-617. 